Originally published as:

Poethko-Müller, C., Mankertz, A.

Sero-epidemiology of measles-specific IgG antibodies and predictive factors for low or missing titres in a German population-based cross-sectional study in children and adolescents (KiGGS) (2011) Vaccine, 29 (45), pp. 7949-7959.

DOI: 10.1016/j.vaccine.2011.08.081

This is an author manuscript.

The definitive version is available at: http://www.sciencedirect.com/ 


\section{Sero-epidemiology of measles-specific IgG antibodies and predictive factors for low or missing titres in a German population-based cross-sectional study in children and adolescents (KiGGS)}

\section{Background and objective:}

In the European Region, measles elimination is now targeted to 2015. To measure progress towards elimination age-group specific susceptibility targets have been defined. Age-specific measles susceptibility in children and adolescents was evaluated in Germany. Taking into account a broad range of socio-demographic, health- and vaccination status related variables, populations for vaccination campaigns were identified.

\section{Method}

We analysed data from children aged 1 to 17 years in the representative German Health Interview and Examination Survey for Children and Adolescents (KiGGS). Measles immunoglobulin $\mathrm{G}$ antibodies were measured in 13,977 participants by enzyme immunoassay (ELISA). Bivariate and multivariate logistic regression analyses were used to determine parental and infant related factors associated with measles susceptibility.

Results

The overall prevalence of seronegativity in children tested for measles IgG aged 1 to 17 years was $10.0 \%$ (95\% CI 9.4-10.7). The prevalence of seronegativity in the German population was below the WHO targets for measles elimination in children aged 2 to 9 year-olds but exceeded the target for 10 to 17 year-olds. Age differences in the level of seronegativity were found to be mainly due to differences in vaccination coverage. A higher level of susceptibility was observed if parents did not comply with the request to present the child's vaccination card. In vaccinated children, immigration, male gender, very young age at first vaccination and a longer time period since last vaccination were associated with a higher level of susceptibility.

\section{Conclusion}

Further increase of the two-dose vaccination coverage is necessary in order to achieve the WHO targets. Catch up vaccination campaigns should focus on adolescents and immigrants. 
1 Sero-epidemiology of measles-specific IgG antibodies and

2 predictive factors for low or missing titres in a German

3 population-based cross-sectional study in children and adolescents

4 (KiGGS)

5

6 Christina Poethko-Müller ${ }^{1}$ and Annette Mankertz ${ }^{2}$

7

8 Robert Koch Institute, Berlin, Germany

9

$10 \quad{ }^{1}$ Department of Epidemiology and Health Reporting

$11 \quad 2$ Division of Viral Infections; NRC MMR and RRL WHO EURO

12 Abstract

13

14 15

16

17 Keywords: Seroprevalence; IgG measles antibodies; vaccination; waning; age at first

18 vaccination; health survey, immunity 


\section{Article Outline}

20 1. Introduction

21 2. Methods

22 2.1. Survey design and study population

23 2.2. Statistical analysis

$24 \quad 2.3$ Laboratory methods

25 3. Results

26 3.1. Seroprevalence of measles antibodies

$27 \quad$ 3.1.1 Seronegativity and WHO target

$28 \quad 3.1 .2$ Seronegativity and documentation of vaccination

29 3.1.3 Positive and negative predictive value of parental report on natural measles $30 \quad$ infection

31 3.1.4 Seroprevalence and socio-demographic and vaccination status related factors

$32 \quad 3.1 .5$ Seroprevalence of neutralising measles antibodies

33 3.1.6 Factors associated with missing measles seroprevalence in vaccinated children

34 4. Discussion

35 5. Conclusions

36 6. References

37

38 1. Introduction

39 Measles, elimination goal:

40 Despite worldwide vaccination activities, measles is still a major cause of death especially in 41 young children. The WHO called into action a program that led to successful elimination in 42 the Americas and a reduction in disease burden in Africa and Asia. Although Europe had 43 targeted measles for elimination by the year 2010, this goal was not met and a new target date 44 for eliminating measles has been set to 2015. Successful elimination will be accredited to the 45 European region when the following criteria have been met: vaccine coverage of more than $4695 \%$, continued disease surveillance with incidence rates below 1 per million population as 47 well as a rate $80 \%$ laboratory confirmed suspected cases. In addition the WHO European 48 Region targets for measles elimination define that the proportion of seronegative children in 
the whole population should not exceed $15 \%$ in children aged $2-4$ years, $<10 \%$ in 5 - to 9 year-olds and $<5 \%$ in older age groups (1).

\section{German situation:}

In Germany, indigenous measles circulation has been interrupted (2), but importation of measles virus (MV) from other countries is common (3). Pockets of susceptible individuals often associated with anthroposophic communities or the catchment area of a naturopathist have experienced MV transmission leading to small and middle-sized outbreaks (4-6). In Germany, a two-dose regime is recommended for measles mumps rubella (MMR) vaccination by the Standing Committee of Vaccination (STIKO). The first dose should be given at months 11-14, the second dose not less than 4 weeks later. MMR immunisation should be completed at the age of 2. Vaccination coverage in Germany has been described in our previous study (7). Besides several smaller outbreaks, a large measles outbreak occurred in North-Rhine Westphalia, Germany in 2006. Analysis of the age distribution revealed that the majority of cases were aged $>9$ years $(8,9)$ and that also a high number of infants was affected. Investigation of a school outbreak in the city of Duisburg displayed major immunisation gaps in older children and young adults. These results indicate a need for further studies in German children, adolescents and young adults to assess the demand on supplementary immunisation activities.

The German Health Interview and Examination Survey for Children and Adolescents (KiGGS) was conducted in a representative sample of children 0-17 years of age. Health related and socio-demographic data plus the vaccination status were recorded. A blood sample was obtained from children aged $>1$. This set-up enabled us for the first time to study the seroprevalence of measles-specific IgG antibodies in a well-defined cohort representative for all children in Germany. Moreover, titres could be correlated to the time point of vaccination and the number of doses administered. Analysing these data, we investigated presence of gaps in seroprevalence in certain age groups and identified factors predicting low measles IgG titre seroprevalence in vaccinated children.

\section{Methods}

\subsection{Survey design and study population}


80 The KiGGS methodology has been described elsewhere $(10,11)$. In brief, the KiGGS survey 81 is based on a nationally representative sample of children and adolescents 0-17 years of age with main residence in Germany. A total of 17,641 children and adolescents were surveyed 8985 boys and 8656 girls. Study participants were enrolled from May 2003 to May 2006. Children and adolescents from families with a non-German nationality were oversampled, as a higher proportion of undeliverable contacts and non-respondents were expected in this subgroup as compared to children from non-migrant families. A migration-specific approach was used and, thus, it was possible to include children with a migration background according to their proportion in the general population. A total of 2,590 children and adolescents with a migration background (both parents) took part in the study (17\%). Another 1,292 children and adolescents $(8.3 \%)$ have one parent with a migration background.

The overall response for eligible children and adolescents was $66.6 \%$ and showed little variation between age groups and sexes, but marked variation between children with and without migration background. Analyses of the short non-responder questionnaires revealed that the collected data give comprehensive and nationally representative evidence on the health status of children and adolescents aged 0 to 17 years.

Questionnaires for children and a parent delivered data on medical history, socioeconomic status, and migration background. Data on vaccination was collected directly from the vaccination cards. The assigned maternal education levels relate to the German school system which provides three different types of secondary education.

In children aged 1 to 17 years, parents and children were asked to consent to taking of a blood sample. In 13,977 (83.7\%) study subjects, a blood sample could be taken and subsequently tested for the presence of measles IgG antibodies. Presented seroprevalence estimates are based on this group. In 13,017 (93.1\%) of children who were tested for measles antibodies, information about vaccinations could be obtained from vaccination cards or parents reported that the children were unvaccinated. Participants with missing or incomplete information on vaccinations were excluded from any further analyses of determinants of seronegativity.

\subsection{Statistical Analysis}

Estimates of vaccination coverage and their confidence intervals (CIs) were calculated using SPSS version 18 (SPSS Inc. Chicago, Illinois). In order to assure that estimates derived from the KiGGS study are representative at the national level, survey weights were applied 
throughout the statistical analyses. Analyses were performed using SPSS Complex Samples procedure and, thus, accounted for the stratified and clustered sample design of our survey. Calculations of the seroprevalence included all children with a known titre, regardless of the quality of their vaccination documentation. In a second step, the seroprevalence of measles antibodies was stratified by socio-demographic factors (sex, age, migration background, maternal education level) and factors related to vaccination status (number of vaccination doses, age at first measles vaccination, years since last measles vaccination, history of a measles infection). In these analyses only children were included for whom a vaccination card was presented or for whom it was reported that they were (still) unvaccinated. The association between seronegativity and different vaccination strategies (number of vaccination doses, age at first measles vaccination), factors known to be associated with measles titre (years since last measles vaccination, history of a measles infection) and factors which may be related to the quality of vaccination (vaccination abroad) or to the probability of natural measles infection and of its perception by parents (foreign born migrants, maternal education level) were analysed by uni- and multivariate regression analyses. These latter analyses were restricted to vaccinated children with valid vaccination documents. Children whose blood sample was taken within 21 days after their first vaccination $(n=30)$ were excluded to avoid inclusion of children in the early immune response phase where antibodies may not be present and serology may therefore be false-negative.

\subsection{Laboratory methods}

\section{Measles IgG ELISA.}

132 The Measles IgG titre of all serum samples was determined by the Siemens Enzygnost anti133 measles IgG test (Siemens, Marburg, Germany) using an automated processor (Tecan 134 Evolyzer, Germany). All samples were tested with kits of the same lot number. The result of the ELISA was expressed quantitatively as an antibody concentration $(\mathrm{mIU} / \mathrm{ml})$ of optical density (OD) according to the manufacturer's instructions. Samples were categorised as seropositive, equivocal or seronegative according to the cut-off values proposed by the manufacturer. Samples with equivocal samples were repeated once. Based on the widely agreed categories for IgG antibody negativity (IgG titre $<150 \mathrm{mIU} / \mathrm{ml}$ ), seropositivity (IgG titre $>350 \mathrm{mIU} / \mathrm{ml}$ ) or equivocal measles antibody levels (IgG titre $150-350 \mathrm{mIU} / \mathrm{ml}$ ), the 
obtained $\mathrm{OD} / \mathrm{IgG}$ titre was categorised taking into account the respective manufacturers correction factors.

Focus of infection reduction neutralisation test (FRNT).

Compared to the ELISA measuring all classes of $\operatorname{IgG}$ able to bind to the respective antigen, the Focus Reduction Neutralisation Test (FRNT) and Plaque Reduction Neutralisation Test (PRNT) quantify only antibodies capable to prevent infection of cells. FRNT and PRNT are known to be more sensitive than ELISA. Recently FRNT was shown to be a good substitute for PRNT for characterising the immune response to mumps and for vaccine efficacy studies (12). Although the FRNT is less laborious than the PRNT, it cannot be used for large numbers of samples. Thus, the FRNT was used to characterise only the sera of patients tested negative in ELISA after vaccination in order to determine whether they had neutralising antibodies. The FRNT was performed as follows: Vero-SLAM cells were seeded in 48 well plates and incubated for $48 \mathrm{~h}$. Serum samples were inactivated for $30 \mathrm{~min}$ at $56^{\circ} \mathrm{C}$ and serially diluted. Edmonston Zagreb (30 pfu in $50 \mu \mathrm{l}$ ) was incubated for $1 \mathrm{~h}$ at $37^{\circ} \mathrm{C}$. Cells were inoculated with $100 \mu \mathrm{l}$ of the serum/virus mixture for $1 \mathrm{~h}$ at $37^{\circ} \mathrm{C}$ in a $\mathrm{CO}_{2}$ incubator and covered with a $500 \mu \mathrm{l}$ overlay of $1 \%$ carboxymethylcellulose (CMC). Cells were incubated for $5 \mathrm{~d}$ at $37^{\circ} \mathrm{C}$ and $5 \% \mathrm{CO}_{2}$. For fixation, cells were washed with cold Phosphate buffered saline (PBS) and covered with $2 \%$ paraformaldehyd for 30 min on ice. Each well was washed with PBS and treated for $10 \mathrm{~min}$ with $200 \mu \mathrm{l}$ methanol at $-20^{\circ} \mathrm{C}$. After a third wash with PBS, $200 \mu \mathrm{l}$ of blocking solution (1\% BSA, 0.5\% FBS, $0.1 \%$ Tween in PBS) was added for 30 min at room temperature (RT). It was replaced by $100 \mu \mathrm{l} /$ well of anti measles $\mathrm{N}$-protein monoclonal antibody (mouse, Chemicon mAb 8906 or ECACC 95040312) diluted 1:500 in blocking solution for $30 \mathrm{~min}$ at RT. Wells were washed twice with blocking solution and incubated for 30 min at RT with $100 \mu 1$ HRP-conjugate (1:1000 in PBS) and subsequently washed twice with $500 \mu 1$ blocking buffer. Five min after the addition of $100 \mu \mathrm{l} \mathrm{MB}$ Blue POD, the wells were rinsed with water. Plaques were counted by eye or under the microscope. Titres were calculated with the formula $0.5(\mathrm{axb} / \mathrm{c}+\mathrm{dxb} / \mathrm{e})=50 \%$ plaque reduction titre according to Ho and Babiuk (13). Plaque reduction titres of $\geq 1: 8$ were considered positive.

\section{Results}




\subsection{Seroprevalence of measles antibodies}

\subsubsection{Seronegativity and WHO target}

Figure 1 shows the percentages of children who displayed a negative or equivocal measles IgG antibody titre by age. This analysis included 13,977 children aged 1-17 year regardless of the presence of a vaccination card.

The overall prevalence of seronegativity in children tested for measles IgG aged 1 to 17 years was $10.0 \%$ (95\% CI 9.4-10.7). In addition, $2.3 \%$ (95\% CI 2.0-2.7) of children displayed an equivocal titre. In 2-4 year old children, the prevalence of seronegativity was, on average, $10.0 \%$ (95\% CI 8.7-11.6). Each age stratum within this age group met the WHO target for seronegativity $(<15 \%)$. The prevalence of seronegativity in 5-9 year old children was, on average, $8.4 \%$ (95\% CI 7.4-9.5). Also in this group each age stratum was below the respective WHO target for seronegativity $(<10 \%)$. The prevalence of seronegativity in 10-17 year old children and adolescents was, on average, $8.3 \%$ (95\% CI 7.6-9.1). In contrast to the younger age groups, each age stratum missed the WHO target for 10 to 19 year olds of $5 \%$. The overall prevalence of an equivocal titre level in children aged 1 to 17 years was $2.3 \%$ (95\% CI 2.02.7). Low titres in vaccinated persons can be a consequence of waning immunity (secondary vaccine failure) or insufficient response to the vaccine (primary vaccine failure). Prevalence of equivocal titres was higher in older children: in 2 to 4 year olds, only $0.8 \%$ (95\% CI 0.5-1.4) had equivocal titres, whereas in 5 to 9 year olds and in 10 to 17 year olds, the proportion was $1.65 \%$ (95\% CI 1.3-2.1) and 3.3\% (95\% CI 2.8-3.9), respectively.

$>$ Figure 1: Seronegativity and equivocal IgG Titre for Measles by age<

\subsubsection{Seronegativity and documentation of vaccination}

Figure 2 shows the proportion of seronegativity in children for whom a vaccination card was provided (or for whom parents reported that they were (yet) unvaccinated) in comparison to children for whom parents did not present a vaccination card at the study centre or for whom the vaccination card was reported to be incomplete. In children aged 1-17 years the proportion of seronegative children was significantly higher in children without a vaccination card (16.0\%; 95\% CI 13.4-19.1) than in children with a valid vaccination card (9.5\%; 95\% CI 8.910.2). Prevalence of seronegativity was especially high in children aged 2-4 and 5-9 years without vaccination cards (24.9\%; 95\% CI $13.8-40.8$ and 22.0\%; 95\% CI 16.2-29.3, 
respectively). No difference was seen among the one year old children; however, in this age group, vaccination cards were unavailable only for 6 children.

$>$ Figure 2: Measles seronegativity by age and by availability of vaccination card $<$

3.1.3 Positive and negative predictive value of parental reports on natural measles infection

Our study comprised a subgroup of 743 unvaccinated children for whom antibody testing was performed and whose parents had reported whether or not their child had a history of measles. In this subgroup were 220 unvaccinated children with positive or equivocal measles antibody titres, 98 of whom were reported to have had measles. The positive predictive value (PPN) for parental reported history of measles infection was 0.79 (Table 1). Of the 613 unvaccinated children whose parents did report no measles infection, 122 children had positive or equivocal measles titre values. We calculated the overall negative predictive value (NPV) to be 0.81 . However, clear differences were detected by age (Table 1). PPV was 0.00 (NPV 0.99) in children aged 1 year, 0.00 (NPV 0.82) in children aged 2-4 years, 0.62 (NPV 0.81) in children aged 5-9 years, 0.75 (NPV 0.72) in children aged 10-13 years and 0.89 (NPV 0.53) in children aged 14- to 17 years.

$>$ Table $1<$

\subsubsection{Seroprevalence and socio-demographic and vaccination status related}

\section{factors}

Table 2 shows the percentages of children who were measles IgG seronegative, equivocal or seropositive by different sociodemographic and vaccination status related factors. The following analyses include only those 13,017 children for whom a vaccination card was presented or for whom it was reported that they were (yet) unvaccinated.

The overall prevalence of seronegativity in children aged 1 to 17 years was $9.5 \%(95 \% \mathrm{CI}$ $8.9-10.2) ; 2.3 \%$ (95\% CI 2.0-2.6) of children displayed an equivocal titre level. The proportion of seronegative children differed by age and was highest in children aged 1 year (39.2\%; 95\% CI 34.2-44.5) and lowest in children aged 5 to 17 years (7.7\%). The proportion of children with equivocal titre level was higher in children older than 10 years than in younger children. Differences in seronegativity were also seen by gender and place of 
residence. Differences were also obvious regarding maternal education level with a high proportion of seronegativity in children of highly educated mothers and a lower proportion in children of mothers with a low education level. A high proportion of immigrated children was seronegative (14.5\%; 95\% CI 10.9-19.1) whereas the prevalence of seronegativity was slightly lower in children with migration background who were born in Germany $(8.2 \%$; 95\% CI 6.99.8) and in children without a migration background (9.5\%; 95\% CI 8.9-10.3). Also the proportion of children with equivocal antibody levels was higher among immigrants.

Seroprevalence differed most by vaccination status. Seronegativity was $68.8 \%$ (95\% CI 65.272.2) in unvaccinated children, 6.5\% (95\% CI 5.4-7.8) in children who had received a single dose vaccination and $4.3 \%$ (95\% CI 3.8-4.9) in children who had received (at least) two vaccination doses. Seroprevalence differed not only by the number of vaccine doses received but also by the time since last vaccination and also by the age of the vaccinee at which the first dose was received. We determined differences by the time since last vaccination stratified accordingly to the number of vaccine doses. In children who had received a two-dose vaccination the prevalence of seronegativity was higher in children who had received their last vaccination 3 to 6 years before the study $(4.5 \%$; 95\% CI 3.8-5.3) and more than six years before the study $(8.4 \%$; $95 \%$ CI 7.0-10.1) in comparison to children who had received their last vaccination less than two years before the study (2.7\%; 95\% CI 2.1-3.4). Corresponding, the proportion of children with equivocal titres was higher the longer the time period since last vaccination had been.

Seroprevalence was also lower in children who had received the first measles vaccination during their first year of life in comparison to children who had received it later. Interestingly, age-related differences at first measles vaccination were also seen within the group of children who had received a second vaccination: $8.9 \%$ (95\% CI 6.7-11.7) of children who had received their first vaccination during their first year of life were seronegative in comparison to $4.0 \%$ (95\% CI 3.5-4.6) of children who received the first vaccination after their first year of life. Antibody levels were also more often equivocal in children who had received their first vaccination at an early age. We observed a linear association between age up to the 17 months at first vaccination and seronegativity in children who had received two measles vaccinations, had their last vaccination no more than six years before the study and had no history of measles infection (Figure 3).

\section{$>$ Figure 3: Seronegativity by age at first vaccination dose<}


In the whole study population, seronegativity was slightly lower in children for whom parents reported a history of measles $(8.0 \%$; $95 \%$ CI $6.1-10.4)$ in comparison to children without a reported history of measles $(9.9 \%$; 95\% CI 9.2-10.6). However, significant differences were only found within the group of unvaccinated children: $81.4 \%$ (95\% CI 77.4-84.8) of children without a history of measles infection were seronegative, whereas only $21.3 \%$ (95\% CI 14.5 30.1) of children whose parents reported a measles history were seronegative. Interestingly, also only $25.9 \%$ (95\% CI 12.4-46.2) of children whose parents were unsure whether their child had had measles were seronegative.

\subsubsection{Seroprevalence of neutralising measles antibodies}

To investigate vaccinated study subjects who showed a negative measles virus antibody value in the ELISA test, several sera were investigated for presence of neutralizing antibodies with the Focus Reduction Neutralisation Test (FRNT). Sera of 30 adolescents above the age of 14 who had $\mathrm{IgG}$ antibody titres below $150 \mathrm{mIU} / \mathrm{ml}$, had their last vaccination more than nine years before the study and had no history of measles were tested by FRNT. Only one out of 30 sera was tested seronegative by FRNT. In the remaining 29 sera, antibodies were detected (1:20-1:274). In 27 of them antibodies were only detectable if dilution was below 1:120.

We also re-analysed 20 sera from children who had received their first vaccination before the age of one year and had received at least two doses of measles vaccine, with the last dose less than three years before the study. These 20 children had IgG measles antibody titres between 4 and $144 \mathrm{mIU} / \mathrm{ml}$ in the ELISA test. Also in this group measles antibodies were detectable by FRNT in all but one child if dilution did not exceed 1:120.

As a control, 25 sera of unvaccinated children aged below 7 years who had an $\operatorname{IgG}$ measles antibody titre of $0-77 \mathrm{mIU} / \mathrm{ml}$ in the ELISA test were tested by FRNT. The FRNT titre was negative $(<1: 8)$ in all of them.

\subsubsection{Factors associated with missing measles seroprevalence in vaccinated}

\section{children}

Considering that measles vaccination is the most important factor associated with seroprevalence of measles antibody titres, we performed detailed uni- and multivariate analyses in children who had received at least one vaccination in order to identify factors 
modifying the odds of a negative antibody titre after vaccination (Table 3 ). These analyses included 12,161 vaccinated children whose blood sample was taken at least 21 days after their first vaccination.

In addition to the variable of parental reported measles infection, factors that were tested statistically significant in the univariate analysis were included in the multivariate analysis. The analysis stratified for single dose or two-dose vaccination schedules indicated that seronegativity was associated with the number of years that had passed since last vaccination: Children who had received their last vaccination more three to six years before the study had a two- to three-fold odds of being seronegative in comparison to children who had received the last (of at least two) vaccination no more than two years before the study (OR 1.95; 95\% CI 1.37-2.77). Children who had received their last vaccination more than six years before the study had a three-fold odds of being seronegative in comparison to children who had received their last vaccination no more than two years before the study (OR 3.67; 95\% CI 2.37-5.69). Seronegativity was more likely in children who had received the first measles vaccination during their first year of life than in children who had received the first dose after the first year of life. The odds of being seronegative after early vaccination was 2.86 (95\% CI 1.64-3.19) for a single dose and was 2.29 (95\% CI 1.64-3.19) for two-dose vaccination.

312 Seronegativity was more likely in children below the age of 2 years (OR 2.38; 95\% CI 1.31313 4.31) than in children aged 10 to 17 years. Boys were more likely to be seronegative than girls 314 (OR 1.33; 95\% CI 1.10-1.61). Immigrants were more likely to be seronegative than children 315 without a migration background (OR 2.35; 95\% CI 1.50-3.69). On the other side, children of 316 immigrants born in Germany were less likely to be seronegative (OR 0.59; 95\% CI 0.40-0.88). 317 A low maternal education level was associated with lower odds for seronegativity in 318 comparison to a medium maternal education level (OR 0.70; 95\% CI 0.52-0.95).

319 In this group of vaccinated children, children whose parents reported a history of measles 320 were no more likely to be seronegative than children whose parents had not reported a history 321 of measles. No statistically significant association was found between seronegativity and place 322 of residence. 


\section{Discussion}

\section{Main results}

The prevalence of seronegativity found in our study was below the WHO European Region targets (1) for measles elimination of $<15 \%$ in children aged 2 to 4 years and $<10 \%$ in 5 to 9 329 year-olds. However, the prevalence of seronegativity in 10 to 17 year-olds seen in our study, 330 exceeded the WHO European Region target of $<5 \%$. The proportion of seronegative children 331 was particularly high in the youngest children (one year of age), indicating a relevant delay of 332 the first measles vaccination which is scheduled in Germany at the age of 11 to 14 months.

333 Seronegativity was lower in children for whom a vaccination card was available compared to 334 those for whom no vaccination card was provided.

335 Seronegativity was highest in unvaccinated children and was (slightly) above the overall 336 WHO target level of $5 \%$ in children who had received a single dose vaccination. 337 Seronegativity was below the target level in children with a two-dose vaccination. Thereby, 338 this large population based sero-epidemiological study supports and confirms once again the 339 crucial importance of a two-dose vaccination schedule to achieve the goal of measles 340 elimination (14-16).

341 We performed multivariate analyses to investigate which vaccination schedule may be associated with low antibody titres and which additional determinants may be associated with an increased risk for seronegativity in the vaccinated German population. Our data may serve as valuable information to public health decision makers to adapt vaccination schedules in order to minimise the time period of susceptibility, the risk for measles infection for individuals amenable to vaccines and the risk and size of measles outbreaks overall. Multivariate analyses showed a three-fold odds of seronegativity in children whose last vaccination had been more than six years before this study. It is remarkable that even in children who received a second vaccination after the first year of life, an early first vaccination was associated with a higher risk of seronegativity.

\section{Strengths and Limitations}

353 Our sero-epidemiological study was conducted in more than 12,000 children and adolescents 354 from the KiGGS survey which were recruited throughout Germany by random population 
based sampling. Our study thereby overcomes the limitation of former seroprevalence studies and can be considered representative for German children and adolescents. Vaccination status was obtained directly by the vaccination records (vaccination card). By using vaccination cards, validity of the date of vaccination and the administered type of vaccine was high and unaffected by recall problems. This allowed us to identify real vaccination failure rates. However, we can not be sure that every vaccination had been documented in the provided vaccination card. Although we excluded children from our analyses whose vaccination cards were reported to be incomplete, completeness could not be systematically ensured. Possible determinants of vaccination success (age at first vaccination, time since last vaccination, one- or two dose vaccination schedule, place of vaccination (abroad or Germany) and ethnic origin) varied considerably. This enabled us to identify populations with a higher proportion of seronegative children and to investigate which determinants may substantially alter the success of vaccination.

In a study of this size, measles IgG antibodies must be measured by an automated ELISA procedure. Since ELISA has a lower sensitivity compared to PRNT, which is considered as the gold standard for determining measles-neutralising serum antibodies (17), seronegative children are not necessarily susceptible to measles. This relevant limitation was overcome by re-testing seronegative subgroups (young age at first vaccination, adolescents suspected to be subject to relevant waning effects) for plaque reduction capacity by FRNT.

ELISA and FRNT cannot differentiate between immunity after vaccination and natural immunity. Since natural infection with measles virus results in a higher titre than the vaccination (18-21), undetected measles wild virus contact may have confounded the study. We tried to minimise this confounding possibility by asking the parents about any clinical history of measles by a standardised interview performed by a physician. Since measles has a very uniform course and subclinical cases are seen only after reinfection or in vaccinees with waning immunity, parents will usually remember a previous primary measles infection and recall bias seems rather unlikely. On the other hand, other rash-fever diseases caused by rubella virus, parvovirus B19 or streptococci may be misdiagnosed as measles if a laboratory based diagnosis is not performed. Data on validity of parent reported infectious disease history are limited and mainly relate to varicella (22). The validity of parent reported information is supported by the fact that the estimated geometric mean titre (GMT) was considerably higher in unvaccinated children for whom a history of measles had been reported in comparison to 
children with vaccine-induced measles antibodies (data not shown). In a subgroup of 743 unvaccinated children whose parents reported whether or not the child had had measles, we estimated the positive and negative predictive values of this parental reported history with lower NPV in adolescents and lower PPV in young children (table 1). Thus, the probabilities of both, unreported wild virus contact and of undocumented vaccination increase with age. These phenomena may have confounded our results.

\section{Waning}

Our study clearly showed that seronegativity increases as time since last vaccination passes. This waning of antibody level was seen in children with a single dose vaccination and also in children with a two dose vaccination schedule and has been shown in many previous studies $(14,23-30)$.

In contrast to the results from (14) who showed a longer half life of seropositivity after twodose vaccination, we found no such difference three years after the last vaccination between children who had received a single vaccination and children who had received a two-dose vaccination. However, the proportion of seronegativity was lower after the two-dose vaccination schedule than after the single-dose schedule. We cannot exclude than any small difference in the decay rate may have went unnoticed as we grouped the time since last vaccination into only three categories $(0-2 ; 3-6$ and $>6$ years since last vaccination) in order to obtain a meaningful size of each stratum for our multivariate analyses.

This study allows for an assessment of the waning effects that occur in a population with a vaccination coverage of almost $95 \%$ for at least one dose of measles vaccine $(31,32)$. We used the most conservative cut-off point of $150 \mathrm{mIU} / \mathrm{ml}$ for protective antibodies against measles disease in our study and excluded equivocal levels $(150-350 \mathrm{mIU} / \mathrm{ml})$. Since it has been demonstrated that vaccinees with an equivocal or even negative titre might nevertheless be protected (33), one cannot conclude that all of these children are susceptible to measles infection.

414 It is widely agreed that the PRNT correlates best with protection (34-38) and it is known that 415 ELISA sensitivity is low especially for samples containing low concentrations of neutralising antibody $(17,39,40)$. Clinical sero-epidemiological analyses using PRNT studying protective antibody titres in outbreaks indicate that a cut-off of $0.2 \mathrm{IU} / \mathrm{ml}$ suggests protection. However, individuals with antibody levels below this threshold may become re-infected and may 
transmit the virus, thereby contributing to enduring circulation and failure of the elimination goal $(35,41,42)$.

Unfortunately, plaque neutralisation tests are costly and labor-intensive. It was therefore not possible to test all sera by PRNT. We did however re-analyse sera of 30 vaccinated adolescents by FRNT who had been tested seronegative by ELISA in order to allow for a better assessment of the susceptibility in children. In 29 of these adolescents, antibodies could be detected in the FRNT. Since FRNT and PRNT use the same test principle and FRNT differs only by the method of detection, it can be assumed that the results of the FRNT are comparable to the PRNT. Nevertheless, it remains questionable if the antibody levels in these adolescents can be considered fully protective (42).

\section{Age at first vaccination}

A number of investigations have shown that immunisation against measles at a very early age is associated with an impaired immune response (23, 43-52). However, data on immune response failure to the second measles vaccination (after an early first vaccination) are not fully conclusive, even if the second vaccination is given in the second year of life or even later. Several studies showed that the immune response to revaccination at an older age was impaired in children who were vaccinated at an early age $(43,51,53,54)$. These results were confirmed by Stetler (55). However, in contrast to the results from Black (53), neutralising antibody tests showed that most children with an impaired immune response after revaccination were successfully primed and probably also protected (55). Two other studies $(44,48)$ found no impaired response to the secondary vaccination in children with an early first dose.

Our study shows that young age at first vaccination is associated with a higher probability of seronegativity, even in children that were revaccinated at an older age (Table 3, Figure 3). These results indicate that mispriming of the immune system after early vaccination cannot be cured by a late second dose of MCV. This finding is alarming, but must be weighed against the benefit for the total population of a shorter window of susceptibility $(54,55)$. Further detailed analyses are therefore necessary. The assessment of the possible effects of early measles vaccination should also take into account work on the age-dependent humoral and cellular immune responses to vaccination $(47,56)$. Low $\operatorname{IgG}$ titres are not necessarily 
equivalent to susceptibility. Especially in young children no correlation between titres measured by PRNT and the IgG response measured by ELISA was seen (57).

To assess whether early vaccinated children may be protected despite a negative ELISA result, we re-analysed sera of 20 children for neutralising antibodies. The results showed that 19 sera were tested positive by FRNT. As it was the case in ELISA negative individuals which were suspected to waning of antibodies with a longer time interval since last vaccination, FRNT was positive, but titres did not exceed the 1:120 border suggested earlier (42). Therefore, neutralising antibodies were detected, but protectivity remains questionable.

\section{Interindividual variations in seronegativity by age, gender and race}

The proportion of seronegative children was highest in the youngest age group and the proportion of an equivocal titre level was highest among adolescents. We identified two main associated factors: a high proportion of (yet) unvaccinated young children and a longer average time period since last vaccination in older children and thus presumably waning titres. However, the odd of being seronegative was higher in the youngest vaccinated children even after controlling for the number of vaccinations, age at first vaccination, years having passed since last vaccination, parent's reported history of a measles infection and other potentially confounding variables (Table 3). Taking into account that the NPV for parental reported measles is lower in adolescents than in young children, it seems plausible that the higher proportion of seronegativity in young children is due to more frequent wild virus measles contact that goes unnoticed by parents in older children and adolescents. In addition, incomplete documentation of vaccination is more likely in older children.

In our study multivariate analyses showed a higher odds of being seronegative in boys than in girls. This result is in line with investigations on sex differences in the humoral antibody response to live measles vaccine in young adults (58), with investigations on sex differences of vaccine efficacy (59), with investigations on sex specific mortality ratios between medium and high titre measles vaccines (60) and with reports of gender specific rates of adverse events after MMR vaccination (61). The mechanisms underlying these gender differences are not completely understood. However, immune responses in general are known to differ by gender and the genetic control of immunoglobulins have been shown to be associated with the $\mathrm{X}$ chromosome (62). An additional contributing factor to a more favourable seroconversion rate in girls could the more rapid loss of maternal measles antibodies in girls (63). As sustaining 
maternal antibodies are assumed to decrease seroconversion rate after vaccination, early vaccinations of girls may lead to higher seroconversion rate than in boys. Immigrant children are at particular risk of incomplete immunisation (7, 64-68). In addition, previous studies support that differences in seronegativity may arise not only from different vaccination coverage but also from genetic factors (69-81). These may be involved in the variation in immune response to measles vaccine in different populations. In our study differences in seronegativity were detected between German-born and foreign-born immigrant children. A possible explanation or contributing fact for this observation may be lower quality of measles vaccine used in other countries, or environmental factors influencing measles vaccine efficacy such as interruption of the cold chain. Inappropriate vaccine storage as a reason for poor vaccine efficacy is supported by data from Latvia which show that MMR vaccine coverage estimates agree with the observed rubella seroprofiles but not with the measles vaccination coverage data. In addition, discrepancies between documented vaccine coverage and seroprevalence data are known from the WHO European Seroepidemiology Network (ESEN2) for Bulgaria, Latvia and Romania (82). Although the data base for our study relied on individual medical records, the quality of foreign vaccination cards may differ from the German documentation in some cases and may have contributed to overestimation of vaccine coverage in immigrant children.

\section{Conclusions}

The prevalence of seronegativity in the German population was below the WHO targets for measles elimination in children aged 2 to 9 year-olds but exceeded the target for 10 to 17 yearolds. Age differences in the level of seronegativity were found to be mainly due to differences in vaccination coverage. However, immigrant children were more often seronegative even if vaccination(s) had been documented. Further increase of the two-dose vaccination coverage is necessary in order to achieve the WHO targets. Catch up vaccination campaigns should focus on adolescents and immigrants.

Our large, representative study showed inferior immune responses in children who were very young age at first vaccination (even if a second vaccination was given at older age). Children 511 who received their first vaccination within the first 12 months of life exceeded the target of 512 less than $5 \%$ seronegativity even if they had a second dose at older ages. We also observed 
waning of antibodies with increasing time since the last vaccination. The prevalence of seronegativity exceeded the WHO target of less than $5 \%$ in those children whose last vaccination dose (single dose or two-dose vaccination) was older than six years.

The protective effect of measles antibodies below the cut-off of $150 \mathrm{mIU} / \mathrm{ml}$ in vaccinated subjects needs to be investigated further.

Our results may contribute to discussions about future adaptations to the current vaccination schedules. Protecting the majority of children at an early age by scheduling the first vaccination within the first year of life has to be traded off against the lower prevalence of seropositivity, especially as failure of the first vaccination cannot be compensated by a second vaccination in a significant proportion of children. This risk assessment will be highly influenced by the measles incidence of a given region. Since measles incidence is still high in Germany, for the time being, reducing the vulnerable time period through early vaccination far outweigh the risk of being seronegative after an early vaccination.

Corresponding author

Christina Poethko-Müller, MD, MSc

Unit 23 "Health of Children and Adolescents, Prevention Concepts"

Dept. of Epidemiology and Health Reporting

Robert Koch Institute

General-Pape Straße 62-66

12101 Berlin

Germany

Phone (++49) 30 18754-3193

Fax: (++49) 3018 / 10-754-3193

E-mail: poethko-muellerc@rki.de

\section{References}

1. Ramsay M. A strategic framework for the elimination of measles in European Region. the Expanded Programme on Immunization in the European Region of WHO (EUR/ICD/CMDS 0101 05). 1999:1-26.

2. Tischer A, Santibanez S, Siedler A, Heider A, Hengel H. Laboratory investigations are indispensable to monitor the progress of measles elimination--results of the German Measles Sentinel 1999-2003. J Clin Virol. 2004 Nov;31(3):165-78.

3. Mankertz A, Mihneva Z, Gold H, Baumgarte S, Baillot A, Helble R, et al. Spread of measles virus D4-Hamburg in Europe. European Infectious Disease 2011;in press.

4. Batzing-Feigenbaum J, Pruckner U, Beyer A, Sinn G, Dinter A, Mankertz A, et al. Spotlight on measles 2010: preliminary report of an ongoing measles outbreak in a 
subpopulation with low vaccination coverage in Berlin, Germany, January-March 2010. Euro Surveill. 2010;15(13).

5. Roggendorf H, Mankertz A, Kundt R, Roggendorf M. Spotlight on measles 2010: measles outbreak in a mainly unvaccinated community in Essen, Germany, March-June 2010. Euro Surveill. $2010 \mathrm{Jul} \mathrm{1;15(26).}$

6. Siedler A, Mankertz A, Ahlemeyer G, Feil F, Hornig A, Scharkus S, et al. Closer to the goal - efforts in measles elimination in Germany 2010. Journal of Infectious diseases. 2011;in press.

7. Poethko - Müller C, Ellert U, Kuhnert R, Neuhauser H, Schlaud M, Schenk L.

Vaccination coverage against measles in German-born and foreign-born children and identification of unvaccinated subgroups in Germany. Vaccine. 2009;27:2563-9.

8. Wichmann O, Hellenbrand W, Sagebiel D, Santibanez S, Ahlemeyer G, Vogt G, et al. Large measles outbreak at a German public school 2006. Pediatr Infect Dis J. 2007 Sep;26(9):782-6.

9. Wichmann O, Siedler A, Sagebiel D, Hellenbrand W, Santibanez S, Mankertz A, et al. Further efforts needed to achieve measles elimination in Germany: results of an outbreak investigation. Bulletin of the World Health Organization. 2009 Feb;87(2):108-15.

10. Kurth BM, Kamtsiuris P, Holling H, Schlaud M, Dolle R, Ellert U, et al. The challenge of comprehensively mapping children's health in a nation-wide health survey: design of the German KiGGS-Study. BMC Public Health. 2008;8:196.

11. Kurth B, Kamtsiuris P, Hölling H, Schlaud M, Dölle R, Ellert U, et al. The challenge of comprehensively mapping children's health in a nation-wide health survey: design and first results of the German KiGGS-Study. BioMed Central Public Health2008. p. 196.

12. Vaidya SR, Brown DW, Jin L, Samuel D, Andrews N, Brown KE. Development of a focus reduction neutralization test (FRNT) for detection of mumps virus neutralizing antibodies. J Virol Methods. 2010 Jan;163(1):153-6.

13. Ho CK, Babiuk LA. A new plaque system for canine distemper: characteristics of the green strain of canine distemper virus. Can J Microbiol. 1979 Jun;25(6):680-5.

14. Lee MS, Chien LJ, Yueh YY, Lu CF. Measles seroepidemiology and decay rate of vaccine-induced measles IgG titers in Taiwan, 1995-1997. Vaccine. 2001 Sep $14 ; 19(32): 4644-51$.

15. Vandermeulen C, Mathieu R, Geert LR, Pierre VD, Karel H. Long-term persistence of antibodies after one or two doses of MMR-vaccine. Vaccine. 2007 Sep 17;25(37-38):6672-6.

16. Pebody RG, Gay NJ, Hesketh LM, Vyse A, Morgan-Capner P, Brown DW, et al. Immunogenicity of second dose measles-mumps-rubella (MMR) vaccine and implications for serosurveillance. Vaccine. 2002 Jan 15;20(7-8):1134-40.

17. Cohen BJ, Parry RP, Doblas D, Samuel D, Warrener L, Andrews N, et al. Measles immunity testing: comparison of two measles IgG ELISAs with plaque reduction neutralisation assay. J Virol Methods. 2006 Feb;131(2):209-12.

18. Brugha R, Ramsay M, Forsey T, Brown D. A study of maternally derived measles antibody in infants born to naturally infected and vaccinated women. Epidemiol Infect. 1996 Dec;117(3):519-24.

19. Christenson B, Bottiger M. Measles antibody: comparison of long-term vaccination titres, early vaccination titres and naturally acquired immunity to and booster effects on the measles virus. Vaccine. $1994 \mathrm{Feb}$;12(2):129-33.

20. Kacica MA, Venezia RA, Miller J, Hughes PA, Lepow ML. Measles antibodies in women and infants in the vaccine era. Journal of medical virology. 1995 Feb;45(2):227-9. 
21. van den Hof S, Berbers GAM, de Melker HE, Conyn-van Spaendonck MAE. Seroepidemiology of measles antibodies in the Netherlands, a cross-sectional study in a national sample and in communities with low vaccine coverage. Vaccine 2000;18:931-40. 22. Diez-Domingo J, Gil A, San-Martin M, Gonzalez A, Esteban J, Baldo JM, et al. Seroprevalence of varicella among children and adolescents in Valencia, Spain. Reliability of the parent's reported history and the medical file for identification of potential candidates for vaccination. Human vaccines. 2005 Sep-Oct;1(5):204-6.

23. Miller E, Hill A, Morgan-Capner P, Forsey T, Rush M. Antibodies to measles, mumps and rubella in UK children 4 years after vaccination with different MMR vaccines. Vaccine. 1995 Jun;13(9):799-802.

24. Theeten H, Hens N, Vandermeulen C, Depoorter AM, Roelants M, Aerts M, et al. Infant vaccination coverage in 2005 and predictive factors for complete or valid vaccination in Flanders, Belgium: an EPI-survey. Vaccine. 2007:4940-8.

25. Mossong J, O'Callaghan CJ, Ratnam S. Modelling antibody response to measles vaccine and subsequent waning of immunity in a low exposure population. Vaccine. 2000 Oct 15;19(4-5):523-9.

26. Pedersen IR, Mordhorst CH, Ewald T, von Magnus H. Long-term antibody response after measles vaccination in an isolated arctic society in Greenland. Vaccine. 1986 Sep;4(3):173-8.

27. Schwarzer S, Reibel S, Lang AB, Struck MM, Finkel B, Gerike E, et al. Safety and characterization of the immune response engendered by two combined measles, mumps and rubella vaccines. Vaccine. 1998 Jan-Feb;16(2-3):298-304.

28. Kremer JR, Schneider F, Muller CP. Waning antibodies in measles and rubella vaccinees--a longitudinal study. Vaccine. 2006 Mar 24;24(14):2594-601.

29. Mossong J, Putz L, Schneider F. Seroprevalence of measles, mumps and rubella antibodies in Luxembourg: results from a national cross-sectional study. Epidemiol Infect. 2004 Jan;132(1):11-8.

30. Davidkin I, Valle M. Vaccine-induced measles virus antibodies after two doses of combined measles, mumps and rubella vaccine: a 12-year follow-up in two cohorts. Vaccine. 1998 Dec;16(20):2052-7.

31. Poethko - Müller C, Kuhnert R, Schlaud M. Vaccination coverage and predictors for vaccination level. Results of the German Health Interview and Examination Survey for Children and Adolescents (KiGGS). Bundesgesundheitsblatt Gesundheitsforschung Gesundheitsschutz. 2007 May-Jun;50(5-6):851-62.

32. Kalies H, Grote V, Schmitt HJ, Kries R. Immunisation status of children in Germany: temporal trends and regional differences. Eur J Pediatr 2006;165(1):30-6.

33. Tischer A, Andrews N, Kafatos G, Nardone A, Berbers G, Davidkin I, et al. Standardization of measles, mumps and rubella assays to enable comparisons of seroprevalence data across 21 European countries and Australia. Epidemiol Infect. 2007 Jul;135(5):787-97.

34. Tischer A, Gerike E. Immune response after primary and re-vaccination with different combined vaccines against measles, mumps, rubella. Vaccine. 2000 Jan 31;18(14):1382-92. 35. Diaz-Ortega JL, Forsey T, Clements CJ, Milstien J. The relationship between dose and response of standard measles vaccines. Biologicals. 1994 Mar;22(1):35-44.

36. Stokes J, Jr., Reilly CM, Buynak EB, Hilleman MR. Immunologic studies of measles. American journal of hygiene. 1961 Nov;74:293-303. 
37. Friedman M.G., Romanova S., Galil A., Sarov B., Dagan R. Comparison of a commercial ELISA kit and a neutralization assay for assessment of humoral immunity to measles virus Serodiagnosis and Immunotherapy in Infectious Disease. 1997;8(3):131-5. 38. Ratnam S, Gadag V, West R, Burris J, Oates E, Stead F, et al. Comparison of commercial enzyme immunoassay kits with plaque reduction neutralization test for detection of measles virus antibody. Journal of clinical microbiology. 1995 Apr;33(4):811-5.

39. Cohen BJ, Doblas D, Andrews N. Comparison of plaque reduction neutralisation test (PRNT) and measles virus-specific IgG ELISA for assessing immunogenicity of measles vaccination. Vaccine. 2008 Nov 25;26(50):6392-7.

40. Tischer A, Gassner M, Richard JL, Suter-Riniker F, Mankertz A, Heininger U.

Vaccinated students with negative enzyme immunoassay results show positive measles virusspecific antibody levels by immunofluorescence and plaque neutralisation tests. J Clin Virol. 2007 Mar;38(3):204-9.

41. Samb B, Aaby P, Whittle HC, Seck AM, Rahman S, Bennett J, et al. Serologic status and measles attack rates among vaccinated and unvaccinated children in rural Senegal. The Pediatric infectious disease journal. 1995 Mar;14(3):203-9.

42. Chen RT, Markowitz LE, Albrecht P, Stewart JA, Mofenson LM, Preblud SR, et al. Measles antibody: reevaluation of protective titers. The Journal of infectious diseases. 1990 Nov;162(5):1036-42.

43. Ceyhan M, Kanra G, Erdem G, Kanra B. Immunogenicity and efficacy of one dose measles-mumps-rubella (MMR) vaccine at twelve months of age as compared to monovalent measles vaccination at nine months followed by MMR revaccination at fifteen months of age. Vaccine. 2001 Aug 14;19(31):4473-8.

\section{Johnson CE, Nalin DR, Chui LW, Whitwell J, Marusyk RG, Kumar ML. Measles} vaccine immunogenicity in 6- versus 15 -month-old infants born to mothers in the measles vaccine era. Pediatrics. 1994 Jun;93(6 Pt 1):939-44.

45. Markowitz LE, Albrecht P, Rhodes P, Demonteverde R, Swint E, Maes EF, et al. Changing levels of measles antibody titers in women and children in the United States: impact on response to vaccination. Kaiser Permanente Measles Vaccine Trial Team. Pediatrics. 1996 Jan;97(1):53-8.

46. Orenstein WA, Markowitz L, Preblud SR, Hinman AR, Tomasi A, Bart KJ. Appropriate age for measles vaccination in the United States. Developments in biological standardization. 1986;65:13-21.

47. Gans HA, Arvin AM, Galinus J, Logan L, DeHovitz R, Maldonado Y. Deficiency of the humoral immune response to measles vaccine in infants immunized at age 6 months. Jama. 1998 Aug 12;280(6):527-32.

48. Carson MM, Spady DW, Albrecht P, Beeler JA, Thipphawong J, Barreto L, et al. Measles vaccination of infants in a well-vaccinated population. The Pediatric infectious disease journal. $1995 \mathrm{Jan} ; 14(1): 17-22$.

49. Pabst HF, Boothe PM, Carson MM. A comparison of alternate immunization regimes for measles in vaccinated populations. Vaccine. 1999 Jan;17(2):182-92.

50. Klinge J, Lugauer S, Korn K, Heininger U, Stehr K. Comparison of immunogenicity and reactogenicity of a measles, mumps and rubella (MMR) vaccine in German children vaccinated at 9-11, 12-14 or 15-17 months of age. Vaccine. $2000 \mathrm{Jul} \mathrm{15;18(27):3134-40.}$ 51. Garly ML, Bale C, Martins CL, Monteiro M, George E, Kidd M, et al. Measles antibody responses after early two dose trials in Guinea-Bissau with Edmonston-Zagreb and Schwarz standard-titre measles vaccine: better antibody increase from booster dose of the Edmonston-Zagreb vaccine. Vaccine. 2001 Feb 28;19(15-16):1951-9. 
52. Zanetta RA, Amaku M, Azevedo RS, Zanetta DM, Burattini MN, Massad E. Optimal age for vaccination against measles in the State of Sao Paulo, Brazil, taking into account the mother's serostatus. Vaccine. 2001 Oct 12;20(1-2):226-34.

53. Black FL, Berman LL, Libel M, Reichelt CA, Pinheiro FD, Travassos da Rosa A, et al. Inadequate immunity to measles in children vaccinated at an early age: effect of revaccination. Bulletin of the World Health Organization. 1984;62(2):315-9.

54. Wilkins J, Wehrle PF. Additional evidence against measles vaccine administration to infants less than 12 months of age: altered immune response following active/passive immunization. The Journal of pediatrics. 1979 Jun;94(6):865-9.

55. Stetler HC, Orenstein WA, Bernier RH, Herrmann KL, Sirotkin B, Hopfensperger D, et al. Impact of revaccinating children who initially received measles vaccine before 10 months of age. Pediatrics. 1986 Apr;77(4):471-6.

56. Nair N, Gans H, Lew-Yasukawa L, Long-Wagar AC, Arvin A, Griffin DE. Agedependent differences in IgG isotype and avidity induced by measles vaccine received during the first year of life. The Journal of infectious diseases. 2007 Nov 1;196(9):1339-45. 57. Kumar ML, Johnson CE, Chui LW, Whitwell JK, Staehle B, Nalin D. Immune response to measles vaccine in 6-month-old infants of measles seronegative mothers. Vaccine. 1998 Dec;16(20):2047-51.

58. Green MS, Shohat T, Lerman Y, Cohen D, Slepon R, Duvdevani P, et al. Sex differences in the humoral antibody response to live measles vaccine in young adults. Int $\mathbf{J}$ Epidemiol. 1994 Oct;23(5):1078-81.

59. Aaby P, Martins C, Bale C, Garly ML, Rodrigues A, Biai S, et al. Sex differences in the effect of vaccines on the risk of hospitalization due to measles in Guinea-bissau. The Pediatric infectious disease journal. 2010 Apr;29(4):324-8.

60. Knudsen KM, Aaby P, Whittle H, Rowe M, Samb B, Simondon F, et al. Child mortality following standard, medium or high titre measles immunization in West Africa. Int $\mathbf{J}$ Epidemiol. 1996 Jun;25(3):665-73.

61. Khalil MK, Al-Mazrou YY, Al-Ghamdi YS, Tumsah S, Al-Jeffri M, Meshkhas A. Effect of gender on reporting of MMR adverse events in Saudi Arabia. East Mediterr Health J. 2003 Jan-Mar;9(1-2):152-8.

62. Rhodes K, Markham RL, Maxwell PM, Monk-Jones ME. Immunoglobulins and the X-chromosome. Br Med J. 1969 Aug 23;3(5668):439-41.

63. Martins C, Bale C, Garly ML, Rodrigues A, Lisse IM, Andersen A, et al. Girls may have lower levels of maternal measles antibodies and higher risk of subclinical measles infection before the age of measles vaccination. Vaccine. 2009 Aug 20;27(38):5220-5. 64. Sun WY, Sangweni B, Butts G, Merlino M. Comparisons of immunisation accessibility between non-US born and US-born children in New York City. Public Health 1998 Nov.;112(6):405-8.

65. Waldhoer T, Haindinger G, Vutue C, Haschke F, Plank R. The impact of sociodemographic variables of immunization coverage of children. European journal of epidemiology. 1997;12:145-9.

66. Chu SY, Barquer LE, Smith PJ. Racial/Ethnic disparities in preschool immunizations: United States, 1996-2001. Am J Public Health. 2004;94:973-7.

67. Borràs E, Domínguez A, Batalla J, Torner N, Cardeñosa N, Nebot M, et al. Vaccination coverage in indigenous and immigrant children under 3 years of age in Catalonia (Spain). Vaccine. 2007 Apr 20;25(16):3240-3.

68. van der Wal MF, Diepenmaat AC, Pel JM, Hirasing RA. Vaccination rates in a multicultural population. Arch Dis Child. 2005 Jan;90(1):36-40. 
69. Coovadia HM, Wesley A, Hammond MG, Kiepiela P. Measles, histocompatibility leukocyte antigen polymorphism, and natural selection in humans. The Journal of infectious diseases. 1981 Aug;144(2):142-7.

70. Galil K, Singleton R, Levine OS, Fitzgerald MA, Bulkow L, Getty M, et al. Reemergence of invasive Haemophilus influenzae type $b$ disease in a well-vaccinated population in remote Alaska. The Journal of infectious diseases. 1999 Jan;179(1):101-6. 71. Hayney MS, Poland GA, Jacobson RM, Schaid DJ, Lipsky JJ. The influence of the HLA-DRB1*13 allele on measles vaccine response. J Investig Med. 1996 Jun;44(5):261-3. 72. Ovsyannikova IG, Jacobson RM, Vierkant RA, Pankratz VS, Poland GA. HLA supertypes and immune responses to measles-mumps-rubella viral vaccine: findings and implications for vaccine design. Vaccine. 2007 Apr 20;25(16):3090-100.

73. Poland GA, Jacobson RM, Colbourne SA, Thampy AM, Lipsky JJ, Wollan PC, et al. Measles antibody seroprevalence rates among immunized Inuit, Innu and Caucasian subjects. Vaccine. 1999 Mar 17;17(11-12):1525-31.

74. Poland GA, Jacobson RM, Schaid D, Moore SB, Jacobsen SJ. The association between HLA class I alleles and measles vaccine-induced antibody response: evidence of a significant association. Vaccine. 1998 Nov;16(19):1869-71.

75. Poland GA, Ovsyannikova IG, Jacobson RM. Application of pharmacogenomics to vaccines. Pharmacogenomics. 2009 May;10(5):837-52.

76. Poland GA, Ovsyannikova IG, Jacobson RM, Vierkant RA, Jacobsen SJ, Pankratz VS, et al. Identification of an association between HLA class II alleles and low antibody levels after measles immunization. Vaccine. 2001 Nov 12;20(3-4):430-8.

77. Poland GA, Sohni Y, Domanico M, Kroning CM, DeGoey SR, Jimale M, et al. High frequency of HLA-A*0103 allele in a Somali population. Human immunology. 2001 Feb;62(2):197-200.

78. Rager-Zisman B, Bazarsky E, Skibin A, Tam G, Chamney S, Belmaker I, et al. Differential immune responses to primary measles-mumps-rubella vaccination in Israeli children. Clinical and diagnostic laboratory immunology. 2004 Sep;11(5):913-8. 79. Siber GR, Santosham M, Reid GR, Thompson C, Almeido-Hill J, Morell A, et al. Impaired antibody response to Haemophilus influenzae type b polysaccharide and low IgG2 and IgG4 concentrations in Apache children. The New England journal of medicine. 1990 Nov 15;323(20):1387-92.

80. Tan PL, Jacobson RM, Poland GA, Jacobsen SJ, Pankratz VS. Twin studies of immunogenicity--determining the genetic contribution to vaccine failure. Vaccine. 2001 Mar 21;19(17-19):2434-9.

81. Thomas C, Moridani M. Interindividual variations in the efficacy and toxicity of vaccines. Toxicology. 2010 Dec 5;278(2):204-10.

82. Andrews N, Tischer A, Siedler A, Pebody RG, Barbara C, Cotter S, et al. Towards elimination: measles susceptibility in Australia and 17 European countries. Bulletin of the World Health Organization. 2008 Mar;86(3):197-204. 
Table 1

Seroprevalence of measles IgG titre in unvaccinated children with and without a history of measles infection by age

\begin{tabular}{|c|c|c|c|c|c|}
\hline \multirow[b]{2}{*}{ Age [years of life] } & \multirow{2}{*}{$\begin{array}{l}\text { parental report of } \\
\text { natural measles } \\
\text { infection }\end{array}$} & \multicolumn{2}{|c|}{ Seroprevalence of measles lgG titre } & \multicolumn{2}{|c|}{ Predictive value of parental report } \\
\hline & & Titre negative & $\begin{array}{l}\text { Titre positive or } \\
\text { equivocal }\end{array}$ & PPV & NPV \\
\hline 1 & yes & & & 0.0 & \\
\hline & $\mathrm{n}=2$ & $100.0 \%$ & $0.0 \%$ & & \\
\hline & no & & & & 0.99 \\
\hline & $n=136$ & $99.3 \%$ & $0.7 \%$ & & \\
\hline $2-4$ & yes & & & 0.0 & \\
\hline & $\mathrm{n}=2$ & $100.0 \%$ & $0.0 \%$ & & \\
\hline & no & & & & 0.82 \\
\hline & $n=138$ & $81.6 \%$ & $18.4 \%$ & & \\
\hline $5-9$ & yes & & & 0.62 & \\
\hline & $\mathrm{n}=20$ & $38.0 \%$ & $62.0 \%$ & & \\
\hline & no & & & & 0.81 \\
\hline & $\mathrm{n}=164$ & $81.4 \%$ & $18.6 \%$ & & \\
\hline $10-13$ & yes & & & 0.75 & \\
\hline & $\mathrm{n}=46$ & $25.0 \%$ & $75.0 \%$ & & \\
\hline & no & & & & 0.72 \\
\hline & $\mathrm{n}=107$ & $72.2 \%$ & $27.8 \%$ & & \\
\hline $14-17$ & yes & & & 0.89 & \\
\hline & $n=60$ & $10.6 \%$ & $89.4 \%$ & & \\
\hline & no & & & & 0.53 \\
\hline & $n=68$ & $53.1 \%$ & $46.9 \%$ & & \\
\hline total $(1-17)$ & yes & & & 0.79 & \\
\hline & $n=130$ & $21.3 \%$ & $78.7 \%$ & & \\
\hline & no & & & & 0.81 \\
\hline & $n=613$ & $81.4 \%$ & $18.6 \%$ & & \\
\hline & total & $70.4 \%$ & $29.6 \%$ & & \\
\hline
\end{tabular}


Seroprevalence of measles IgG titre in children with documentation of vaccinations by socio-demografic variables and vaccination status

\begin{tabular}{|c|c|c|c|c|}
\hline & $\begin{array}{c}\text { Number of cases } \\
\text { unweighted }\end{array}$ & $\begin{array}{c}\text { Titre negative } \\
<150 \mathrm{mIU} / \mathrm{ml}^{*}(95 \% \\
\mathrm{Cl})\end{array}$ & $\begin{array}{c}\text { Titre borderline } \\
150-350 \mathrm{mlU} / \mathrm{ml}^{*} \\
(95 \% \mathrm{Cl})\end{array}$ & $\begin{array}{l}\text { Titre positive } \\
>350 \mathrm{mlU} / \mathrm{ml}^{*} \\
\quad(95 \% \mathrm{Cl})\end{array}$ \\
\hline Total & 13,017 & $9.5 \%(8,9-10.2)$ & $2.3 \%(2.0-2.6)$ & $88.2 \%(87.5-88.9)$ \\
\hline \multicolumn{5}{|l|}{ Gender } \\
\hline female & 6,349 & $8.8 \%(8.1-9.6)$ & $2.3 \%(1.9-2.7)$ & $88.9(88.0-89.7)$ \\
\hline \multicolumn{5}{|l|}{ age (years) } \\
\hline 1 & 456 & $39.2 \%(34.2-44.5)$ & $0.9 \%(0.3-3.0)$ & $59.9(54.3-65.1)$ \\
\hline $2-4$ & 1,894 & $9.6 \%(8.2-11.1)$ & $0.8 \%(0.4-1.3)$ & $89.7 \%(88.1-91,1)$ \\
\hline $5-9$ & 4,082 & $7.7 \%(6.6-8.8)$ & $1.7 \%(1.3-2.2)$ & $90,7 \%(89.4-91,8)$ \\
\hline $10-17$ & 6,585 & $7.7 \%(7.0-8.5)$ & $3.2 \%(2.7-3.8)$ & $89.1 \%(88.1-89.9)$ \\
\hline \multicolumn{5}{|l|}{ place of residence } \\
\hline former East & 4,522 & $7,8 \%(6.9-8.7)$ & $2.8 \%(2.2-3.6)$ & $89.4 \%(88.4-90.4)$ \\
\hline former West & 8,495 & $9,9 \%(9.2-10.6)$ & $2.2 \%(1.8-2.6)$ & $87.9 \%(87.1-88.7)$ \\
\hline \multicolumn{5}{|c|}{ migration background (one sided and two sided) } \\
\hline German-born & 2,053 & $8.2 \%(6.9-9.8)$ & $1.0 \%(0.6-1.6)$ & $90.8 \%(89.1-92.2)$ \\
\hline foreign-born & 383 & $14.5 \%(10,9-19.1)$ & $8.0 \%(5.4-11.6)$ & $77.5 \%(72.5-81.9)$ \\
\hline no migration background & 10,427 & $9.5 \%(8,9-10.3)$ & $2.4 \%(2.0-2.8)$ & $88.1 \%(87.3-88.9)$ \\
\hline \multicolumn{5}{|l|}{ Maternal education level } \\
\hline high & 3,61 & $11.2 \%(10.1-12.4)$ & $2.3 \%(1.7-3.0)$ & $86.5 \%(85.1-87.8)$ \\
\hline medium & 6,09 & $9.4 \%(8.5-10.4)$ & $2.4 \%(2.0-2.9)$ & $88.2 \%(87.1-88.2)$ \\
\hline low & 2,741 & $8.0 \%(7.0-9.2)$ & $2.0 \%(1.5-2.7)$ & $90.0 \%(88.6-91.2)$ \\
\hline \multicolumn{5}{|l|}{ vaccination status } \\
\hline unvaccinated & 827 & $68.8 \%(65.2-72.2)$ & $0.8 \%(0.4-1.6)$ & $30.4 \%(27.1-34.0)$ \\
\hline single dose vaccination & 2,467 & $6.5 \%(5.4-7.8)$ & $2.4 \%(1.7-3.2)$ & $91.1 \%(89.6-92.5)$ \\
\hline $\begin{array}{l}\text { two-dose (or more) vaccination } \\
\text { years since last vaccination } \\
\text { one dose }\end{array}$ & 9,723 & $4.3 \%(3.8-4.9)$ & $2.4 \%(2.0-2.8)$ & $93.3 \%(92.6-93.9)$ \\
\hline years since last vaccination $0-2$ & 798 & $6.7 \%(4.8-9.1)$ & $1.4 \%(0.7-2.8)$ & $91.9 \%(89.0-94.1)$ \\
\hline years since last vaccination 3-6 & 679 & $6.0 \%(4.0-8.9)$ & $1.4 \%(0.8-2.7)$ & $92.6 \%(89.5-94.8)$ \\
\hline years since last vaccination >6 & 972 & $6.9 \%(5.3-8.9)$ & $3.7 \%(2.5-5.5)$ & $89.4 \%(87.0-91.4)$ \\
\hline \multicolumn{5}{|l|}{ two (or more) doses } \\
\hline years since last vaccination $0-2$ & 4,192 & $2.7 \%(2.1-3.4)$ & $1.4 \%(1.0-1.8)$ & $96.0 \%(95.2-96.6)$ \\
\hline years since last vaccination $3-6$ & 4,154 & $4.5 \%(3.8-5.3)$ & $2.9 \%(2.3-3.6)$ & $92.6 \%(91.7-93.5)$ \\
\hline years since last vaccination $>6$ & 1,373 & $8.4 \%(7.0-10.1)$ & $4.1 \%(3.1-5.5)$ & $87.4 \%(85.3-89.3)$ \\
\hline \multicolumn{5}{|l|}{$\begin{array}{l}\text { age at first measles vaccination } \\
\text { one dose }\end{array}$} \\
\hline first dose aged 0-11 months & 80 & $14.4 \%(7.4-26.4)$ & $1.8 \%(0.4-7.4)$ & $83.8 \%(71.9-91.3)$ \\
\hline first dose aged $1-17$ years & 2,369 & $6.3 \%(5.2-7.7)$ & $2.4 \%(1.7-3.3)$ & $91.3 \%(89.7-92.7)$ \\
\hline \multicolumn{5}{|l|}{ two (or more) doses } \\
\hline first dose aged 0-11 months & 656 & $8.9 \%(6.7-11.7)$ & $3.5 \%(2.2-5.6)$ & $87.6 \%(84.7-90.0)$ \\
\hline first dose aged $1-17$ years & 8,958 & $4.0 \%(3.5-4.6)$ & $2.3 \%(2.0-2.7)$ & $93.7 \%(93.0-94.3)$ \\
\hline \multicolumn{5}{|l|}{ history of measles infection } \\
\hline no & 10,787 & $9.9 \%(9.2-10.6)$ & $2.3 \%(1.9-2.7)$ & $87.9 \%(87.1-88.7)$ \\
\hline yes & 772 & $8.0 \%(6.1-10.4)$ & $2.0 \%(1.1-3.4)$ & $90.1 \%(87.2-92.3)$ \\
\hline $\begin{array}{r}\text { Don't know } \\
\text { unvaccinated }\end{array}$ & 478 & $6.6 \%(4.6-9.3)$ & $2.3 \%(1.2-4.2)$ & $91.1 \%(87.8-93.6)$ \\
\hline no & 613 & $81.4 \%(77.4-84.8)$ & $0,6 \%(0,2-1,5)$ & $18.0 \%(14.6-22.0)$ \\
\hline yes & 130 & $21.3 \%(14.5-30.1)$ & $0,0 \%$ & $78.7 \%(69.9-85.5)$ \\
\hline $\begin{array}{r}\text { Don't know } \\
\text { vaccinated }\end{array}$ & 771 & $25.9 \%(12.4-46.2)$ & $3.5 \%(0.5-21.4)$ & $70.6 \%(50.2-85.2)$ \\
\hline no & 10,174 & $4.8 \%(4.2-5.4)$ & $2.4 \%(2.0-2.8)$ & $92.9 \%(92.1-93.5)$ \\
\hline yes & 642 & $5.0 \%(3.5-7.2)$ & $2.4 \%(1.4-4.2)$ & $92.6 \%(89.8-94.6)$ \\
\hline Don't know & 450 & $5.0 \%(3.3-7.6)$ & $2.2 \%(1.1-4.2)$ & $92.8 \%(89.3-95.2)$ \\
\hline
\end{tabular}


Table 3

Uni- and Multivariate odds ratios (OR) for the association between sociodemographic and medical variables, vaccination status and the risk of negative measles antibody titres $(\mathrm{lgG}<150 \mathrm{mlU} / \mathrm{ml})$ in vaccinated children

\begin{tabular}{|c|c|c|c|c|}
\hline & $\begin{array}{l}\text { univariate OR } \\
(95 \% \mathrm{Cl})\end{array}$ & $\mathrm{p}$ Value & $\begin{array}{l}\text { multivariate } \mathrm{OR}^{*} \\
(95 \% \mathrm{Cl})\end{array}$ & $\mathrm{p}$ Value \\
\hline Gender & \multicolumn{3}{|c|}{0.015} & 0.004 \\
\hline male & $1.33(1.10-1.60)$ & & $1.33(1.10-1.61)$ & \\
\hline female & Referent & & Referent & \\
\hline age (years) & & $<0.001$ & & 0.024 \\
\hline 1 & $1.31(0.80-2.16)$ & & $2.38(1.31-4.31)$ & \\
\hline $2-4$ & $0.52(0.36-0.75)$ & & $1.09(0.65-1.83)$ & \\
\hline $5-9$ & $0.64(0.49-0.82)$ & & $0.99(0.74-1.34)$ & \\
\hline $10-17$ & Referent & & Referent & \\
\hline \multicolumn{2}{|l|}{ place of residence } & 0.78 & & \\
\hline $\begin{array}{r}\text { former East } \\
\text { former West }\end{array}$ & $\begin{array}{r}\text { Referent } \\
1.03(0.82-1.30)\end{array}$ & & & \\
\hline \multicolumn{2}{|c|}{ migration background (one sided and two sided) } & $<0.001$ & & $<0.001$ \\
\hline German-born & $0.52(0.37-0.73)$ & & $0.59(0.40-0.88)$ & \\
\hline foreign-born & $2.48(1.68-3.66)$ & & $2.35(1.50-3.69)$ & \\
\hline no migration background & Referent & & Referent & \\
\hline \multicolumn{2}{|l|}{ Maternal education level } & 0.038 & & 0.06 \\
\hline high & $0.82(0.64-1.06)$ & & $0.83(0.64-1.08)$ & \\
\hline medium & Referent & & Referent & \\
\hline low & $0.71(0.54-0.93)$ & & $0.70(0.52-0.95)$ & \\
\hline \multicolumn{5}{|l|}{ years since last vaccination } \\
\hline one dose & & $<0.001$ & & $<0.001$ \\
\hline years since last vaccination $0-2$ & $1.71(1.08-2.70)$ & & $1.39(0.85-2.28)$ & \\
\hline years since last vaccination 3-6 & $2.31(1.43-3.72)$ & & $2.92(1.74-4.89)$ & \\
\hline years since last vaccination $>6$ & $2.70(1.89-3.85)$ & & $3.05(1.88-4.93)$ & \\
\hline \multicolumn{5}{|l|}{ two (or more) doses } \\
\hline years since last vaccination $0-2$ & Referent & & Referent & \\
\hline years since last vaccination $3-6$ & $1.70(1.33-2.18)$ & & $1.95(1.37-2.77)$ & \\
\hline years since last vaccination $>6$ & $3.35(2.43-4.62)$ & & $3.67(2.37-5.69)$ & \\
\hline $\begin{array}{l}\text { age at first measles vaccination } \\
\text { one dose }\end{array}$ & & $<0.001$ & & $<0.001$ \\
\hline age at first dose $<12$ months & $4.03(1.86-8.74)$ & & $2.86(1.18-7.00)$ & \\
\hline age at first dose $>11$ months & $1.41(1.09-1.83)$ & & $1.00(1.00-1.00)$ & \\
\hline \multicolumn{5}{|l|}{ two (or more) doses } \\
\hline age at first dose $<12$ months & $2.33(1.66-3.26)$ & & $2.29(1.64-3.19)$ & \\
\hline age at first dose $>11$ months & Referent & & Referent & \\
\hline history of measles infection & & 0.848 & & 0.973 \\
\hline no & $0.90(0.61-1.35)$ & & $0.95(0.63-1.44)$ & \\
\hline yes & Referent & & Referent & \\
\hline Don't know & $0.99(5.90-1.68)$ & & $0.98-0.56-1.74)$ & \\
\hline
\end{tabular}

* Adjusted for gender, age, migration background, maternal education level, years since last measles vaccination, age at first measles vaccination, parental report on history of measles infection 
Figure 1

Seronegativity and equivocal IgG Titre for Measles by age

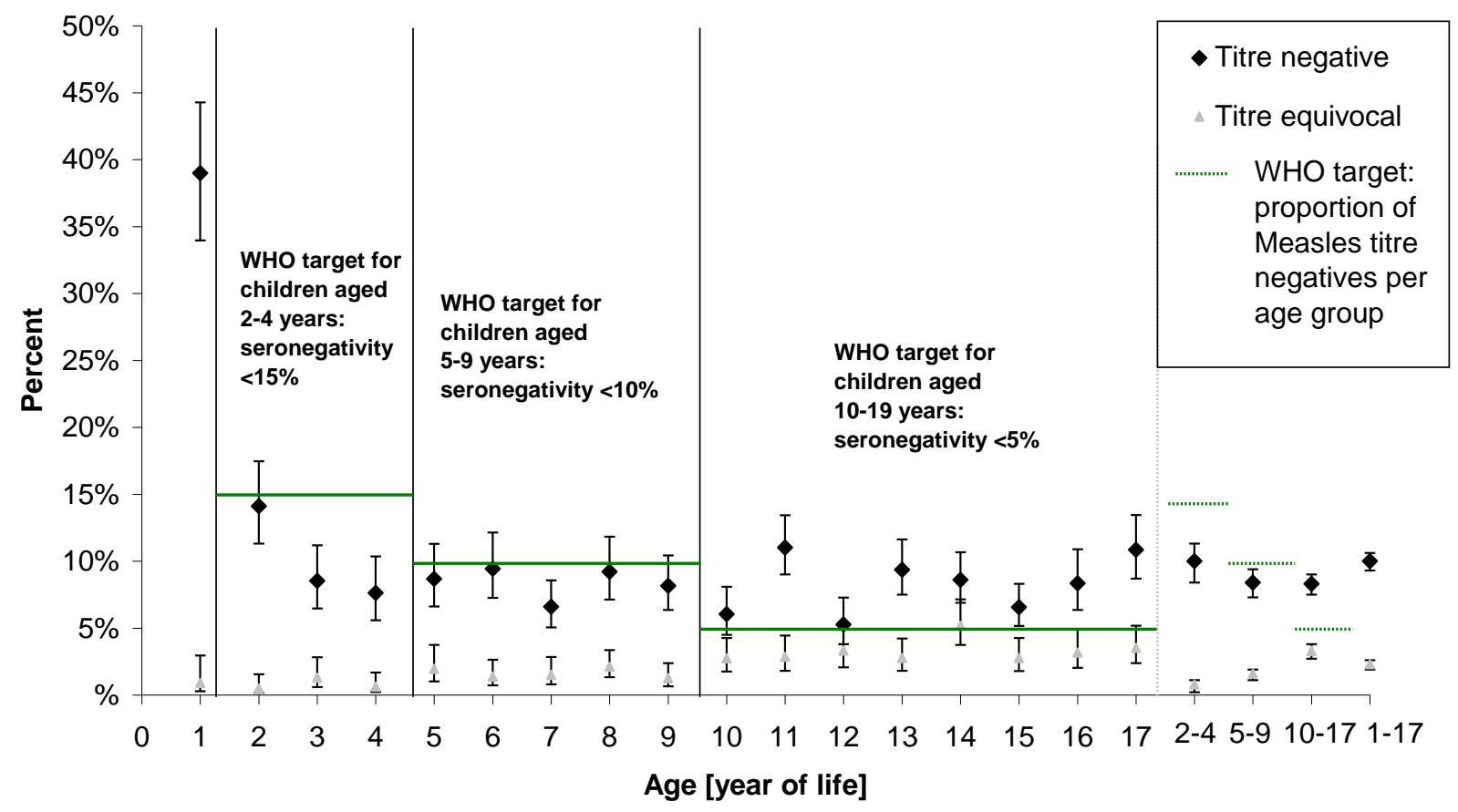




\section{Figure 2}

Measles seronegativity by age and by availability of vaccination card

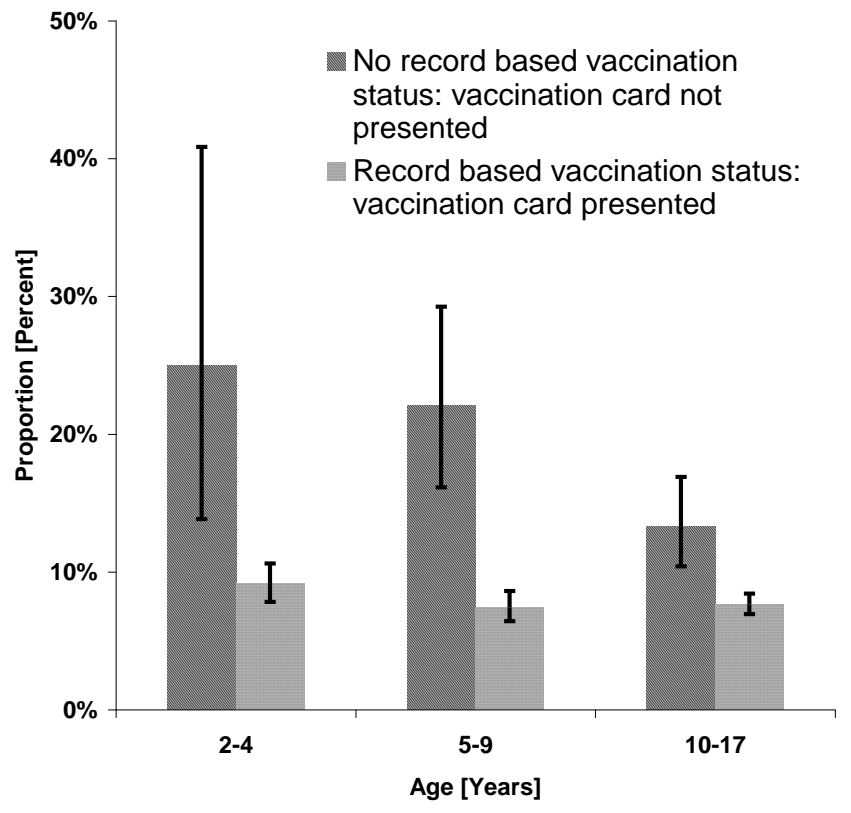


Figure 3

Seronegativity by age at first vaccination dose $(n=7001$, age $1-17$, at least two doses measles vaccine, last dose within last 6 years, no measles disease reported)

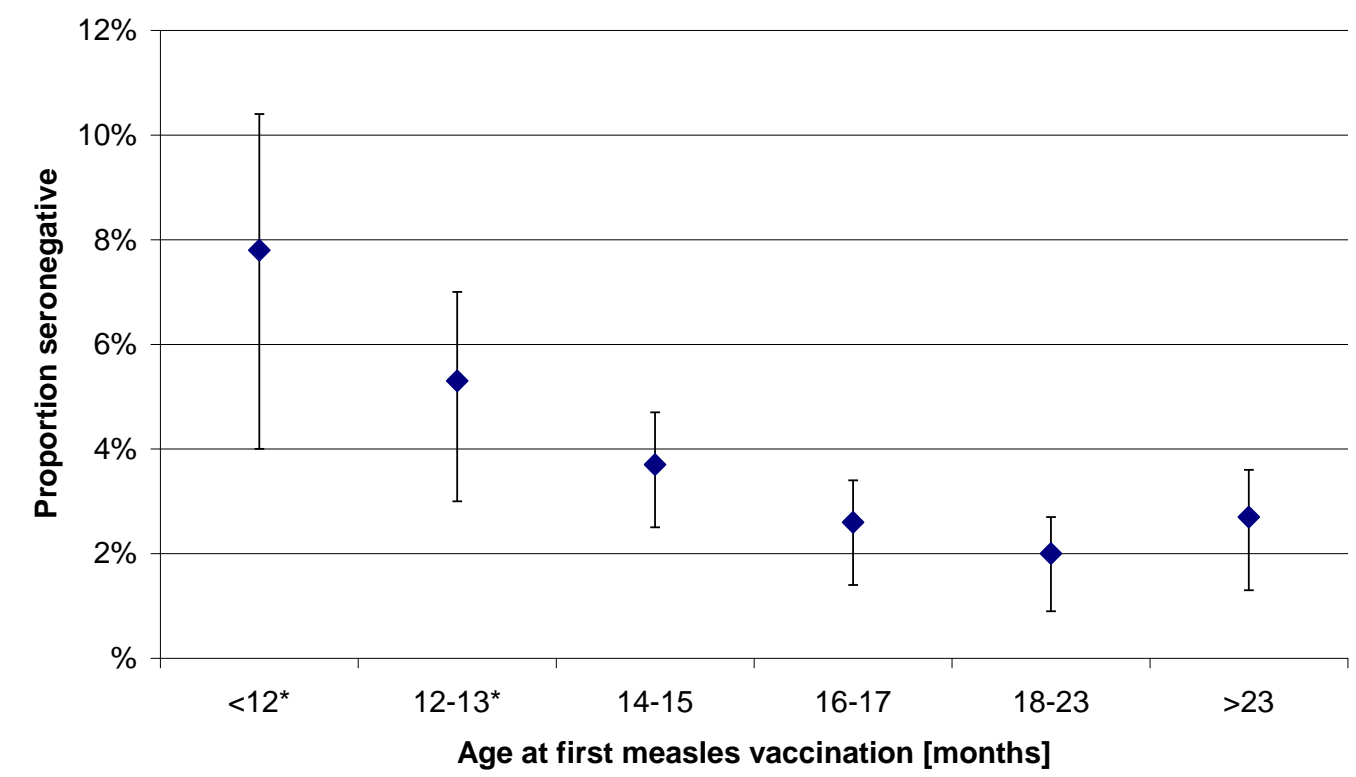

* Statistically significant $p<0.05$; t-test; reference: age at first dose $>23$ months 